Disclosure of Interest: None declared

DOI: 10.1136/annrheumdis-2018-eular.5341

\section{SAT0217 IDENTIFICATION OF DISTINCT DISEASE ACTIVITY TRAJECTORIES IN PATIENTS WITH RHEUMATOID ARTHRITIS RECEIVING TOFACITINIB OVER 12 MONTHS}

V. P. Bykerk ${ }^{1}$, R. van Vollenhoven ${ }^{2}$, C. Connell ${ }^{3}$, D. Gruben ${ }^{3}$, L. Fallon ${ }^{4}$, J. Woolcott ${ }^{5}$, E. Keystone ${ }^{6}$. ${ }^{1}$ Weill Cornell Medical College, New York, NY, United States, ${ }^{2}$ Amsterdam Rheumatology and Immunology Center, Amsterdam, Netherlands, ${ }^{3}$ Pfizer Inc, Groton, CT, United States, ${ }^{4}$ Pfizer Canada, Montreal, QC Canada, ${ }^{5}$ Pfizer Inc, Collegeville, PA, United States, ${ }^{6}$ Mount Sinai Hospital, Toronto, ON, Canada

Background: Persistence of active disease in patients (pts) with rheumatoid arthritis (RA) is highly variable following treatment initiation. One possible explanation is the existence of distinct disease activity/response trajectories influenced by baseline variables, such as sociodemographics, disease characteristics and health status. ${ }^{1}$

Objectives: To identify distinct disease activity trajectories over 12 months and distinguishing baseline factors using pooled data from 3 randomised, controlled Phase 3 (P3) studies of tofacitinib $5 \mathrm{mg}$ twice daily (BID) in pts with active RA who were inadequate responders (IR) to conventional synthetic (cs)DMARDs, with or without prior biologic (b)DMARDs (NCT00847613, NCT00856544 and NCT00853385).

Methods: Disease Activity Score in 28 joints, erythrocyte sedimentation rate (DAS28-4[ESR]) data from 3 P3 studies were pooled. A group-based trajectory modelling strategy was applied to find unique longitudinal groups of pts with similar disease activity over time. ${ }^{2}$ Trajectories were latent models, fit as polynomials. The number of groups and polynomial degree of each group were specified and fit for all combinations of up to 6 groups and up to a 4th degree polynomial; a best-fit model was chosen using Bayesian information criteria.

Results: csDMARD-IR/bDMARD-naïve pts $(n=677)$ were separated into 5 unique disease activity trajectories (figure 1); csDMARD-IR pts who received prior bDMARDs $(n=149)$ were separated into 4 trajectories (not shown). In the bDMARD-naïve pts, Group 5 (3.8\%) had the highest predicted baseline DAS (7.3) with minimal improvement (6.4) at Month 12; Group 4 (26.7\%) had baseline DAS 7.0, improving to DAS 5.0 at Month 12 ; Groups $2(30.4 \%)$ and $3(36.6 \%)$ had baseline DAS 5.9 and 6.2, respectively, leading to low DAS (2.9) and moderate DAS (3.9), respectively, at Month 12; Group 1 (2.4\%) had the lowest baseline DAS of 4.3, improving to remission (DAS 2.1) at Month 12 (figure 1). The 4 trajectories in cSDMARD-IR pts who received prior bDMARDs were similar to Groups $2-5$ in bDMARD-naïve pts. While baseline demographics were generally similar between bDMARD-naïve groups, there were statistically significant differences in baseline disease activity measures and pt-relevant outcomes between groups.

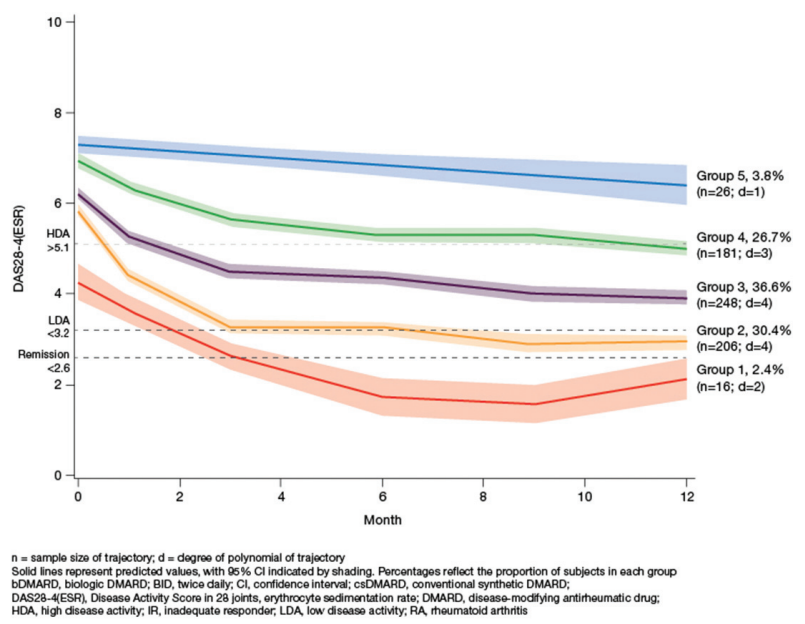

Figure 1. Predicted group trajectories based on DAS28-4(ESR) with $95 \% \mathrm{Cl}$ identified using group-based trajectory modeling in patients with active RA who were csDMARD-IR and bDMARD-naïve and receiving tofacitinib $5 \mathrm{mg} B I D n=$ sample size of trajectory; $d$ = degree of polynomial of trajectory

Conclusions: It was possible to identify heterogeneous phenotypic subgroups as distinct disease activity trajectories in cSDMARD-IR pts treated with tofacitinib.
The groups were characterised by differences in disease activity and pt-relevant outcomes, including baseline pain and physical function. Very high disease activity may limit pts' ability to achieve low disease activity. The identification of distinct trajectory groups could be used to develop personalised treatment optimisation algorithms incorporating clinical and molecular phenotypes.

\section{REFERENCES :}

[1] Barnabe C, et al. PLoS One 2015;10:e0135327.

[2] Nagin DS. In: Handbook of Quantitative Criminology. New York, NY Springer 2010:53-67.

Acknowledgements: Study sponsored by Pfizer Inc. Medical writing support was provided by R Knight of CMC and funded by Pfizer Inc.

Disclosure of Interest: V. Bykerk Grant/research support from: Amgen, BMS, Genentech, UCB, Consultant for: AbbVie, Amgen, BMS, Gilead, Pfizer Inc, Sanofi-Regeneron, UCB, R. van Vollenhoven Grant/research support from: AbbVie, Amgen, BMS, GSK, Pfizer Inc, Roche, UCB, Consultant for: AbbVie, AstraZe neca, Biotest, BMS, Celgene, Crescendo, Eli Lilly, GSK, Janssen, Merck Novartis, Pfizer Inc, Roche, UCB, Vertex, C. Connell Shareholder of: Pfizer Inc, Employee of: Pfizer Inc, D. Gruben Shareholder of: Pfizer Inc, Employee of: Pfize Inc, L. Fallon Shareholder of: Pfizer Inc, Employee of: Pfizer Inc, J. Woolcott Shareholder of: Pfizer Inc, Employee of: Pfizer Inc, E. Keystone Grant/research support from: AbbVie, Amgen, BMS, Eli Lilly, Pfizer Inc, Roche, Consultant for: AbbVie, Amgen, BMS, Eli Lilly, Pfizer Inc, Roche

DOI: 10.1136/annrheumdis-2018-eular.1281

\section{SAT0218 EFFICACY AND SAFETY OF BARICITINIB IN MTX-IR PATIENTS WITH RHEUMATOID ARTHRITIS: 52 WEEK RESULTS FROM A PHASE 3 STUDY (RA-BALANCE)}


G. Wang ${ }^{11}$, J. Sun ${ }^{12}$, F. Ji ${ }^{12}$, H. Tao ${ }^{12}$, L. Zhan ${ }^{12}$, T. Rooney ${ }^{13}$, C. Zerbini ${ }^{14}$.

${ }^{1}$ Peking University People's Hospital, Beijing, ${ }^{2}$ Pingxiang People's Hospital, Pingxiang, ${ }^{3}$ Renji Hospi. Affliated to SH Jiaotong U, Shanghai, ${ }^{4}$ Qilu Hospital of Shandong University, Shandong, ${ }^{5}$ Anhui Provincial Hospital, ${ }^{6} 1$ st Affiliate Hospital of AnHui Med U, Anhui, China, ${ }^{7}$ Centro Medico Privado de Reumatologica, Tucuman, Argentina, ${ }^{8}$ Guangdong General Hospital, Guangdong, ${ }^{9} 1$ st Affiliated Hospital of Kunming Med U, Kunming, ${ }^{10} 1$ st Afflilated Hospital of Bengbu Med C, Anhui, ${ }^{11}$ China-Japan Friendship Hospital, Beijing, ${ }^{12}$ Eli Lilly and Company, Shanghai, China, ${ }^{13}$ Eli Lilly and Company, Indianapolis, United States, ${ }^{14}$ Centro Paulista de Investigacao Clinica, São Paulo, Brazil

Background: Baricitinib (BARI) is an oral selective inhibitor of Janus kinase 1 (JAK1) and JAK2. In the EU and some other countries, baricitinib has been approved for the treatment of moderately to severely active rheumatoid arthritis (RA) in adult patients. This abstract reports efficacy and safety results from a phase 3, double-blinded, 52-week study (RA-BALANCE) that enrolled patients (pts) in China, Argentina and Brazil (NCT02265705).

Objectives: To assess the efficacy and safety of BARI vs placebo (PBO) in the treatment of RA.

Methods: Patients with moderately to severely active RA (tender joint counts $\geq 6$ \& swollen joint counts $\geq 6$ \& hsCRP $\geq 6 \mathrm{mg} / \mathrm{L}$ ) despite stable background methotrexate (MTX), were randomized 1:1 to PBO $(n=145)$ or BARI 4-mg $(n=145)$ once daily (QD), stratified by country and baseline joint erosion status. Background MTX was continued. Non-responders were rescued from Week 16. At Week 24 pts receiving PBO were switched to BARI 4-mg QD. ACR20 at Week 12 was the primary endpoint and there were multiple secondary endpoints e.g., assessing physical function, low disease activity and pain

Results: The primary ACR20 response was significantly greater for BARI than PBO $(58.6 \%$ vs $28.3 \%, \mathrm{p} \leq 0.001$, Table). At Weeks 12 and 24 , significant improvements were seen in pts receiving BARI vs PBO for ACR20/50/70, DAS28-hsCRP, CDAl low disease activity and SDAI low disease activity, many as early as by Week 1. At Week 16, significantly less radiographic progression was seen in pts receiving $B A R I$ vs $P B O$ and numerical improvement was observed at Week 24. At Week 12, significant improvement in HAQ-DI minimum clinically important difference $\geq 0.3$ (physical function), duration of morning joint stiffness, severity of morning joint stiffness numeric rating scale (NRS), worst tiredness NRS and reduced pain (0-100 mm VAS) were seen in pts receiving BARI vs PBO

During Weeks $0-24$, treatment emergent adverse events and infections were reported in $74.5 \%$ and $42.1 \%$ of BARI pts and $62.1 \%$ and $28.3 \%$ of PBO pts, respectively. Serious adverse events were reported in $2.8 \%$ of pts in both groups. There was 1 nonserious esophageal candidiasis in the BARI group for Week 0 24. Four herpes zoster events (1 PBO, 3 BARI) were reported for Week 0-24. No major cardiovascular events, deaths, tuberculosis, venous thromboembolic 
events or malignancies were reported in the study through Week 24 for PBO and through Week 52 for BARI group. No unexpected safety signals were observed.

Table 1. Study RA-BALANCE efficacy measures

\begin{tabular}{|c|c|c|c|c|c|}
\hline & \multicolumn{2}{|c|}{ Week 12} & \multicolumn{2}{|c|}{ Week 24} & \multirow{2}{*}{\begin{tabular}{|c|} 
Week 52t \\
BARI \\
(N=145)
\end{tabular}} \\
\hline & \begin{tabular}{|c|} 
PBO \\
$(\mathrm{N}=145)$
\end{tabular} & $\begin{array}{c}\text { BARI } \\
(\mathrm{N}=145)\end{array}$ & $\begin{array}{c}\text { PBO } \\
(\mathrm{N}=145)\end{array}$ & $\begin{array}{c}\text { BARI } \\
(\mathrm{N}=145)\end{array}$ & \\
\hline ACR20, $n(\%)$ & $\begin{array}{c}41 \\
(28.3)\end{array}$ & $\begin{array}{c}85 \\
(58.6)^{+2 *}\end{array}$ & $\begin{array}{c}47 \\
(32.4)\end{array}$ & $\begin{array}{c}93 \\
(64.1)^{\operatorname{mat}}\end{array}$ & $\begin{array}{c}91 \\
(62.8)\end{array}$ \\
\hline ACR50, $n(\%)$ & $\begin{array}{c}12 \\
(8.3)\end{array}$ & $\begin{array}{c}44 \\
(30.3)^{m \times}\end{array}$ & $\begin{array}{c}17 \\
(11.7)\end{array}$ & $\begin{array}{c}56 \\
(38.6)^{\operatorname{man}}\end{array}$ & $\begin{array}{c}68 \\
(46.9)\end{array}$ \\
\hline ACR70, $n(\%)$ & $\begin{array}{c}2 \\
(1.4)\end{array}$ & $\begin{array}{c}14 \\
(9.7)^{* *}\end{array}$ & $\begin{array}{c}6 \\
(4.1)\end{array}$ & $\begin{array}{c}27 \\
(18.6)^{+20+0}\end{array}$ & $\begin{array}{c}36 \\
(24.8)\end{array}$ \\
\hline DAS28-hsCRP $\leq 3.2, \mathbf{n}(\%)$ & $\begin{array}{c}13 \\
(9.0)\end{array}$ & $\begin{array}{c}36 \\
(24.8)^{\operatorname{san}}\end{array}$ & $\begin{array}{c}15 \\
(10.3)\end{array}$ & $\begin{array}{c}51 \\
(35.2)^{n+\infty}\end{array}$ & $\begin{array}{c}67 \\
(46.2)\end{array}$ \\
\hline DAS28-hsCRP <2.6, n (\%) & $\begin{array}{c}4 \\
(2.8)\end{array}$ & $\begin{array}{c}17 \\
(11.7)^{2 *}\end{array}$ & $\begin{array}{l}10 \\
(6.9)\end{array}$ & $\begin{array}{c}21 \\
(14.5)^{*}\end{array}$ & $\begin{array}{c}48 \\
(33.1)\end{array}$ \\
\hline CDAI $\leq 10, n(\%)$ & $\begin{array}{c}13 \\
(9.0)\end{array}$ & $\begin{array}{c}26 \\
(17.9)^{*}\end{array}$ & $\begin{array}{l}13 \\
(9.0)\end{array}$ & $\begin{array}{c}39 \\
(26.9)^{\mathrm{mat}}\end{array}$ & $\begin{array}{c}67 \\
(46.2)\end{array}$ \\
\hline SDAI s11, n (\%) & $\begin{array}{l}12 \\
(8.3)\end{array}$ & $\begin{array}{c}30 \\
(20.7)^{* *}\end{array}$ & $\begin{array}{l}14 \\
(9.7)\end{array}$ & $\begin{array}{c}40 \\
(27.6)^{\operatorname{mat}}\end{array}$ & $\begin{array}{c}67 \\
(46.2)\end{array}$ \\
\hline HAQ-DI MCID $\geq 0.22, n(\%)$ & $\begin{array}{c}89 \\
(61.4)\end{array}$ & $\begin{array}{c}102 \\
(70.3)\end{array}$ & $\begin{array}{c}51 \\
(35.2)\end{array}$ & $\begin{array}{c}94 \\
(64.8)^{\operatorname{sen} x}\end{array}$ & $\begin{array}{c}89 \\
(61.4)\end{array}$ \\
\hline HAQ-DI MCID $\geq 0.3, n(\%)$ & $\begin{array}{c}67 \\
(46.2)\end{array}$ & $\begin{array}{c}90 \\
(62.1)^{\mu * *}\end{array}$ & $\begin{array}{c}45 \\
(31.0)\end{array}$ & $\begin{array}{c}85 \\
(58.6)^{200}\end{array}$ & $\begin{array}{c}83 \\
(57.2)\end{array}$ \\
\hline $\begin{array}{l}\text { LS mean } \Delta \text { Patient's Assessment of Pain } \\
(0.100 \mathrm{~mm} \mathrm{VAS})^{*}\end{array}$ & -17.7 & $-31^{n+x}$ & -20.1 & $-34.8^{\operatorname{san} x}$ & -40.2 \\
\hline $\begin{array}{l}\text { LS mean } \Delta \text { Patient's Global Assessment of Disease Activity } \\
(0.100 \mathrm{~mm} \text { VAS })^{s}\end{array}$ & .20 .0 & $-31.3^{n+\infty}$ & -18.5 & $-33.4^{4+\infty}$ & -37.8 \\
\hline
\end{tabular}

PBO, placebo; BARI, baricitinib; MCID, minimum clinically important difference; VAS, visual analogue scale. Patients received stable background MTX throughout the study. Data are \% patients (NRI), u
"Data are least-squares (LS) mean change from baseline; tlnitially randomized to baricitinib.

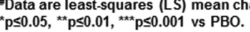

Conclusions: Compared to PBO, BARI provided significant improvements in control of signs and symptoms, including pain and physical function with an acceptable safety profile.

Disclosure of Interest: Z. Li Consultant for: Advisory board member of baricitinib, J. Hu: None declared, C. Bao Consultant for: Advisory board member of baricitinib, X. Li Consultant for: Advisory board member of baricitinib, X. Li Consultant for: Advisory board member of baricitinib, J. Xu: None declared, A. Spindler: None declared, X. Zhang Consultant for: Advisory board member of baricitinib, J. Xu Consultant for: Advisory board member of baricitinib, Z. Li Consultant for: Advisory board member of baricitinib, G. Wang Consultant for: Advisory board member of baricitinib, J. Sun Shareholder of: Eli Lilly and company, Employee of: Eli Lilly and company, F. Ji Shareholder of: Eli Lilly and company, Employee of: Eli Lilly and company, H. Tao Shareholder of: Eli Lilly and company, Employee of: Eli Lilly and company, L. Zhan Employee of: Eli Lilly and company, T. Rooney Shareholder of: Eli Lilly and company, Employee of: Eli Lilly and company, C. Zerbini Grant/ research support from: Grants for research received by my research center CEPIC, for teriparatide and baricitinib protocols, Consultant for: Advisory board member of baricitinib

DOI: 10.1136/annrheumdis-2018-eular.1983

\section{SAT0219 UPADACITINIB IN PATIENTS WITH ACTIVE RHEUMATOID ARTHRITIS AND INADEQUATE RESPONSE OR INTOLERANCE TO BIOLOGICAL DMARDS: A PHASE 3 RANDOMIZED, PLACEBO- CONTROLLED, DOUBLE-BLIND STUDY OF A SELECTIVE JAK1 INHIBITOR}

M. C. Genovese ${ }^{1}$, R. Fleischmann ${ }^{2}$, B. Combe ${ }^{3}$, S. Hall ${ }^{4}$, Y. Zhang ${ }^{5}$, Y. Zhou ${ }^{5}$, M. F. Mohamed ${ }^{5}$, S. Meerwein ${ }^{6}$, A. L. Pangan ${ }^{5} .{ }^{1}$ Stanford Univ, Palo Alto, ${ }^{2}$ Univ of Texas Southwestern, Dallas, United States, ${ }^{3}$ Montpellier Univ, Montpellier, France, ${ }^{4}$ Monash Univ, Cabrini Health \& Emeritus Res, Malvern, Australia, ${ }^{5}$ AbbVie, $N$ Chicago, United States, ${ }^{6}$ AbbVie Deutschland, Ludwigshafen, Germany

Background: Upadacitinib (UPA), an oral, selective JAK1 inhibitor was effective in ph 2 trials in rheumatoid arthritis (RA) pts with inadequate response (IR)/intolerance to csDMARDs and bDMARDs.

Objectives: To evaluate safety and efficacy of UPA in bDMARD-IR pts on stable background csDMARDs

Methods: Pts with active RA ( $T J C \geq 6, S J C \geq 6$; $h s C R P \geq 3 \mathrm{mg} / \mathrm{L}$ ) were randomized 2:2:1:1 to receive UPA $15 \mathrm{mg}$ or $30 \mathrm{mg}$ once daily (QD) or PBO for 12 wks followed by UPA $15 \mathrm{mg}$ or $30 \mathrm{mg}$ QD starting at Wk 12 . The primary endpoints were the proportion of pts achieving ACR20 (for FDA) and the proportion achieving DAS28CRP $\leq 3.2$ (for EMA) at Wk 12 (NRI).

Results: Of 499 randomized pts, 498 received study drug; 451 (90.6\%) and 419 (84.1\%) completed Wks 12 and 24 respectively. BL disease characteristics indicated long-standing severe, refractory disease: (means) duration since diagnosis 13 yrs; DAS28CRP, 5.8; TJC68, 27.9; SJC66, 16.8; 53\% experienced $\geq 2$ prior bDMARDs. At Wk 12 , more pts $(p<0.001)$ on UPA 15 and 30 vs PBO achieved the primary endpoints (ACR20: $64.6 \%$ and $56.4 \%$ vs $28.4 \%$; DAS28CRP $\leq 3.2: 43.3 \%$ and $42.4 \%$ vs $14.2 \%$ ) and other secondary endpoints (Table). Among pts with IR to multiple bDMARDs/MOAs, and pts with lack of efficacy for $\alpha-$ IL-6, the proportions achieving ACR20 on UPA vs PBO were comparable to the overall treated population. By Wk 1, more pts achieved ACR20 on UPA 15 and 30 vs PBO ( $27.4 \%$ and $24.8 \%$ vs $10.7 \%, p<0.001)$. At Wk 12 , significant improvements were observed on UPA 15 and 30 vs PBO for HAQ-DI (LSM change -0.39 and -0.42 vs $-0.17, p<0.001$ ). At Wk 24 , responses were similar or greater for pts originally on UPA and comparable for pts who switched to UPA after 12 wks of PBO

Up to wk 12, the frequency of AEs was comparable for PBO and UPA 15, but higher for UPA 30 (table 1). Overall AE rates (E/100 PY) through Wk 24 for UPA 30 were similar or slightly higher vs UPA 15; more AEs led to study drug discontinuation in UPA 30. Occurrence of infections was similar in all arms, but there were more serious infections and herpes zoster cases in UPA 30. Malignancies were reported in 3 pts over 12 wks with 1 additional case through Wk 24. Through Wk 12, pulmonary embolism (PE) was reported in 2 pts (1 each on UPA 15 and 30 ), none with DVT; through Wk 24, PE were reported in 4 more pts (UPA 15: 3, 1 of whom also had a DVT; UPA 30:1). All had risk factors for DVT/PE. 2 deaths were reported (UPA30: 1 before Wk 12; UPA 15:1 after Wk12)

\begin{tabular}{|c|c|c|c|c|c|c|c|}
\hline \multicolumn{8}{|c|}{ Efficacy Measures'; Percentage of Patients with a Response } \\
\hline & \multicolumn{3}{|c|}{ Week 12} & \multicolumn{4}{|c|}{ week 24} \\
\hline & \begin{tabular}{|l|}
$P B O$ \\
$N=169$
\end{tabular} & $\begin{array}{l}\text { UPA } 15 \\
n=164\end{array}$ & $\begin{array}{l}\text { UPA } 30 \\
N=165\end{array}$ & $\begin{array}{l}\text { PEOG } \\
\text { UPA 15 } \\
N=85\end{array}$ & $\begin{array}{c}\mathrm{PBO} \rightarrow \\
\text { UPA } 30 \\
N=84\end{array}$ & $\begin{array}{l}\text { UPA } 15 \\
N=164\end{array}$ & $\begin{array}{l}\text { UPA } 30 \\
N=165\end{array}$ \\
\hline ACR20 & 28.4 & $64.6^{* 1 *}$ & $56.4 * *$ & 51.2 & 63.1 & 61.6 & 59.4 \\
\hline DAS28-CRPS3.2 & 14.2 & $43.3^{* \cdots}$ & $424^{* \cdots}$ & 38.8 & 56.0 & 52.4 & $\$ 15$ \\
\hline ACR5O & 11.8 & $1 \cdots$ & $35.8^{*} \cdots$ & 5.3 & 38.1 & 42.7 & 3.0 \\
\hline ACR 70 & 65 & 116 & $23.0 \%$ & 2.4 & 21.4 & 22.0 & 4.2 \\
\hline COAI $\leq 10$ & 14.2 & $317 \cdots$ & $33.9^{* *}$ & 34.1 & 53.6 & 47.0 & 43.6 \\
\hline COAI $\leq 28$ & 47 & 7.9 & & & 14.3 & 10.4 & 5.2 \\
\hline DAS28-CRP $<2.6$ & 9.5 & $28.7 \cdots$ & $23.6 \cdots$ & 28. & 34.5 & 32 & 34.5 \\
\hline $\begin{array}{l}\text { ACR } 20 \text { in ots wh o f folled } 22 \\
\text { bDMARDS and } \alpha 223 \mathrm{MOA}\end{array}$ & 23.1 & 708 & 50.0 & - & - & - & - \\
\hline $\begin{array}{l}\text { ACR20 in pts with LoE for } \\
\text { anti-1L6 }\end{array}$ & 200 & 556 & 581 & - & - & - & - \\
\hline \multicolumn{8}{|l|}{ Summ ary of AEs, $n(\$ \%)$} \\
\hline & \multicolumn{3}{|c|}{ Week 0.12} & \multicolumn{4}{|c|}{ Week 12-24 } \\
\hline & $\begin{array}{c}\text { PSO } \\
N=169\end{array}$ & $\begin{array}{l}\text { UPA 15 } \\
N=164\end{array}$ & $\begin{array}{l}\text { UPA } 30 \\
N=165\end{array}$ & $\begin{array}{l}P B O \rightarrow \\
\text { UPA 15 } \\
\|=72\end{array}$ & $\begin{array}{l}P B O \rightarrow \\
\text { UPA } 30 \\
\mu=75\end{array}$ & $\begin{array}{c}\text { UPA } \\
15 \\
N=156\end{array}$ & $\begin{array}{c}\text { UPA } \\
30 \\
n=148\end{array}$ \\
\hline AES & 95 & 91 & 3) & $30(41.7)$ & $50(66.7)$ & $82(52.6)$ & $83(56.1)$ \\
\hline AE Leosin & $9(5.3)$ & $4(2$ & 15 & $2(2.8)$ & 30 & $5(3.2)$ & \\
\hline \multirow{2}{*}{\multicolumn{8}{|c|}{ Patients with Adverse fvents of Special interest, $n(\$ 0)$}} \\
\hline & & & & & & & \\
\hline Infection & $51(302)$ & $54(32.9)$ & $55(33.3)$ & $16(22.2)$ & $31(41,3)$ & $43(27.6)$ & $47(31.8)$ \\
\hline - Seria & 0 & & & $2(2.8)$ & $1(1,3)$ & $1(0.6)$ & $2(1.4)$ \\
\hline - Oppor & 0 & & & 0 & 0 & 0 & $1(0.7)$ \\
\hline - Herpe & $1(0.6)$ & $\frac{110}{110}$ & $4(2.4)$ & 0 & $1(1,3)$ & $2(1.3)$ & $2(1.4)$ \\
\hline- Tube & 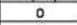 & 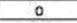 & & & & 0 & 0 \\
\hline Malignancy (exc NMSC) & 0 & $1(0.6)$ & $2(12)$ & & & $1(0.6)$ & 0 \\
\hline NMSC & 0 & 0 & 0 & 0 & 0 & 0 & 0 \\
\hline $\operatorname{trmg}$ & 0 & & & 0 & 0 & 0 & \\
\hline Hepar & $2(1.2)$ & $2(1,2)$ & $3(18)$ & 0 & $2(2.7)$ & $4(2.6)$ & $4(2.7)$ \\
\hline Gl Perforatic & 0 & 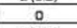 & 0 & 0 & 0 & 0 & $1(0.7)$ \\
\hline$P E$ & 0 & & 10.6 & $2(28)^{9}$ & $1(1,3)$ & $1(0.6)$ & 0 \\
\hline CV Events adjudiczed $d^{g}$ & 0 & 110.6 &  & 0 & $1(2.3)$ & $2(1.3)$ & 0 \\
\hline Deaths ${ }^{\circ}$ & 0 & 0 & $1(06)$ & 0 & 0 & $1(0.6)$ & 0 \\
\hline \multicolumn{8}{|c|}{ 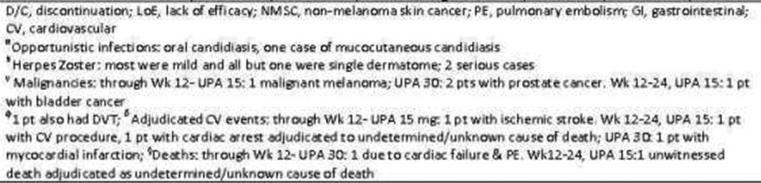 } \\
\hline
\end{tabular}

Conclusions: In this treatment-refractory, bDMARD-IR RA population, rapid, significant improvements were observed with UPA at both doses vs PBO during 12 wks of treatment, and maintained through 24 wks. Overall safety was consis tent with ph2 and other ph3 studies with UPA. The rates of PE and DVT observed in this study have not been reported for the other ph3 studies that have been unblinded to date. Overall data from the ph3 program will allow a comprehensive evaluation of the benefit:risk profile of UPA in RA.

Acknowledgements: AbbVie sponsored study design, data collection, analysis \& interpretation, writing, review, approval of final. Med writing:Naina Barretto of AbbVie

Disclosure of Interest: M. Genovese Grant/research support from: AbbVie Lilly, Pfizer, Galapagos, Gilead, Consultant for: AbbVie, Lilly, Pfizer, Galapagos, Gilead, R. Fleischmann Grant/research support from: AbbVie, Consultant for: AbbVie, B. Combe Consultant for: Abbvie, BMS, Jansen, Lilly, MSD, Pfizer Roche Chugai, UCB, S. Hall: None declared, Y. Zhang Shareholder of: AbbVie, Employee of: AbbVie, Y. Zhou Shareholder of: AbbVie, Employee of: AbbVie, M. Mohamed Shareholder of: AbbVie, Employee of: AbbVie, S. Meerwein Shareholder of: AbbVie, Employee of: AbbVie, A. Pangan Shareholder of: AbbVie, Employee of: AbbVie

DOI: 10.1136/annrheumdis-2018-eular.4180 